\title{
Prospect of in vitro Bile Fluids Collection in Improving Cell-Based Assay of Liver Function
}

\begin{abstract}
Astia Rizki-Safitri ${ }^{1 \star \dagger}$, Fumiya Tokito ${ }^{1}$, Masaki Nishikawa ${ }^{1}$, Minoru Tanaka ${ }^{2,3}$, Kazuya Maeda ${ }^{4}$, Hiroyuki Kusuhara ${ }^{4}$ and Yasuyuki Sakai ${ }^{1}$

${ }^{1}$ Department of Chemical System Engineering, Graduate School of Engineering, The University of Tokyo, Tokyo, Japan, ${ }^{2}$ Laboratory of Stem Cell Regulation, Institute for Quantitative Biosciences (IQB), The University of Tokyo, Tokyo, Japan, ${ }^{3}$ Department of Regenerative Medicine, Research Institute, National Center for Global Health and Medicine (NCGM), Tokyo, Japan, ${ }^{4}$ Laboratory of Molecular Pharmacokinetics, Graduate School of Pharmaceutical Sciences, The University of Tokyo, Tokyo, Japan
\end{abstract}

OPEN ACCESS

Edited by:

Hajime Kojima,

National Institute of Health Sciences

(NIHS), Japan

Reviewed by:

Takuo Ogihara,

Takasaki University of Health and

Welfare, Japan

Albert P. Li,

In Vitro ADMET Laboratories,

United States

*Correspondence:

Astia Rizki-Safitri

astiars@chemsys.t.u-tokyo.ac.jp

${ }^{\dagger}$ Present address: Astia Rizki-Safitri,

Nephrology Division, Harvard Medica

School, Massachusetts General Hospital, Boston, MA, United States

Specialty section: This article was submitted to

In Vitro Toxicology,

a section of the journal

Frontiers in Toxicology

Received: 22 January 2021 Accepted: 26 April 2021

Published: 03 June 2021

Citation:

Rizki-Safitri A, Tokito F, Nishikawa M, Tanaka M, Maeda K, Kusuhara H and Sakai Y (2021) Prospect of in vitro Bile

Fluids Collection in Improving Cell-Based Assay of Liver Function.

Front. Toxicol. 3:657432.

doi: 10.3389/ftox.2021.657432
The liver plays a pivotal role in the clearance of drugs. Reliable assays for liver function are crucial for various metabolism investigation, including toxicity, disease, and pre-clinical testing for drug development. Bile is an aqueous secretion of a functioning liver. Analyses of bile are used to explain drug clearance and related effects and are thus important for toxicology and pharmacokinetic research. Bile fluids collection is extensively performed in vivo, whereas this process is rarely reproduced as in the in vitro studies. The key to success is the technology involved, which needs to satisfy multiple criteria. To ensure the accuracy of subsequent chemical analyses, certain amounts of bile are needed. Additionally, non-invasive and continuous collections are preferable in view of cell culture. In this review, we summarize recent progress and limitations in the field. We highlight attempts to develop advanced liver cultures for bile fluids collection, including methods to stimulate the secretion of bile in vitro. With these strategies, researchers have used a variety of cell sources, extracellular matrix proteins, and growth factors to investigate different cell-culture environments, including three-dimensional spheroids, cocultures, and microfluidic devices. Effective combinations of expertise and technology have the potential to overcome these obstacles to achieve reliable in vitro bile assay systems.

Keywords: in vitro, bile fluids collection, liver culture, liver function analyses, cell-based assay

\section{INTRODUCTION}

The liver is one of the largest glands in the body and is pivotal to various metabolic functions, including blood glucose regulation, protein synthesis, and detoxification. These functions are mainly performed within the hepatocyte parenchymal cells. Hepatocytes are responsible for $40-$ $70 \%$ of the xenobiotic liver metabolism (Almazroo et al., 2017). Therefore, analyses of hepatocyte functions can be used for toxicities assay.

Presence of liver diseases or injuries also frequently alters the amount and composition of liver secretions (Luo et al., 2018). A functional liver produces bile, a secretion containing 95\% water that dissolves bile acids (BAs), bilirubin, ions, hormones, and other metabolites. BAs are major organic solutes, mainly consisting of cholic acid and chenodeoxycholic acid. BAs and bile are secreted into the canaliculi structure of hepatocytes prior to entering the biliary system in the liver (Boyer, 2013; Chiang, 2013). Although bile formation is a common process in normal livers, 
it is impaired in cases of cholestatic liver disease (Boyer, 2013). The presence of drugs or liver injuries (Luo et al., 2014; Ni et al., 2016) has been widely reported to alter the amount as well as the composition (Luo et al., 2014) and perturbation of BA in the bile fluids (Rodrigues et al., 2014). Thus, bile is used as a source for enzymatic assays (Cell Biolabs Inc, 2017), profiling (Samer et al., 2013; Luo et al., 2014; Bathena et al., 2015), and uptakeefflux testing (Yang et al., 2017). Many bile tests have employed in vivo collection using both non-invasive and invasive procedures. Non-invasive procedures include urine (Griffiths and Sjövall, 2010; Hofmann and Hagey, 2014; Bathena et al., 2015), fecal recovery (Ghibellini et al., 2006; Griffiths and Sjövall, 2010), and Entero ${ }^{\circledR}$ testing (Bloomer et al., 2013). Meanwhile, invasive procedures employ serum collections (Luo et al., 2014), biliary sphincterotomies (Navaneethan et al., 2014), duodenal fluid collection, nasobiliary drainage, and cholecystectomies (Bloomer et al., 2013).

In vitro liver research has been subjected to long-term projects for the establishment of standard preclinical assays that are still widely implemented in pharmaceutical studies. The in vitro liver model offers time efficient results and is flexible for human tissues (Soldatow et al., 2013). It is simple, controllable (Xu et al., 2014), allows for intensive analyses (Fatehullah et al., 2016), and exhibits accurate dose-response relationships related to drug analyses (Soldatow et al., 2013). However, bile fluids collection and testing is rarely constructed in an in vitro model. The low amount of bile yields, as represented by the BA concentrations from recovered culture media (Marion et al., 2012) and auto-toxic conjugatedBA produced in culture (Woolbright et al., 2015, 2016) has hindered its further consideration. In this paper, we discuss the current research that both directly and indirectly addresses liver-functional bile production in vitro.

\section{BILE COLLECTION FROM IN VITRO LIVER CULTURE}

\section{Characterization of Drug-Induced Liver Toxicity Mechanism Through Biliary Secretion}

Elucidation of the biliary excretion process is important because it leads to an understanding of drug-induced liver toxicity. BAs are often used as an index for this purpose and are found in blood samples collected from test subjects. They can be evaluated as a biomarker in vivo (Wolenski et al., 2017; Luo et al., 2018; Liu et al., 2020). This biomarker can be used to predict biliary excretion because some drugs inhibit the bile salt export pump (BSEP). BSEP is an excretion transporter of hepatocytes for Bas, which induces perturbations of biliary excretion (Funk et al., 2001; Kemp and Brouwer, 2004; Wolenski et al., 2017). Conversely, the use of an in vitro liver culture system could provide a more detailed understanding of the biliary excretion process from a molecular biological perspective. For example, it can better detect the transporters involved in bile excretions and their inhibitions caused by drugs (Funk et al., 2001; Kemp and Brouwer, 2004). However, with in vitro liver models, because there are no outlets for biliary metabolites in most cases, biliary metabolites accumulate in the bile canaliculi between adjacent hepatocytes, preventing accurate evaluation of drug-induced hepatotoxicity. Additionally, the lack of outlets for biliary metabolites restricts development of in vitro models for studying the effects of enterohepatic circulation of biliary metabolites, which have the potential to amplify drug toxicity.

\section{Increase in New Drug Development}

Because the development of a new drug generally takes more than 10 years and can cost more than USD 1B (Hughes et al., 2011), it is desirable to have a system that could evaluate pharmacokinetics more accurately and at a lower cost. To predict the pharmacokinetics of drugs in the human body, experimental animals (e.g., mice and rats) are often used. The advantages of doing so are two-fold. First, one can understand the pharmacokinetics (i.e., absorption, distribution, metabolism, and excretion) in the whole body and not just at specific locations. Second, one can implement realistic toxicity studies of oral and inhalation exposures (Barré-Sinoussi and Montagutelli, 2015). However, the problem of species differences cannot be overcome. Moreover, there have been some cases where side effects and immune responses that were not seen in non-clinical animal studies were found in clinical studies in humans (van Norman, 2019). Another issue is the cost and labor required for animal breeding, breeders, and proper breeding environments. Conversely, the use of human cells cultured on Petri dishes can solve these issues while elucidating the local mechanism of pharmacological action (Funk et al., 2001; Kemp and Brouwer, 2004). Development of physiologically relevant in vitro liver models is desired because the liver plays a central role in drug metabolism. For the accurate prediction of pharmacokinetics, an in vitro liver model should be able to distinguish whether the parent's metabolized drugs were excreted into the blood or bile. In these models, biliary metabolites could be collected directly.

\section{Need for Enhancing Bile Collection in vitro}

Bile fluids collection in vitro has limitations. The amount of fluids collected from the culture medium is suggestively low, as presented by BA concentrations in the bile at $<1$ $\mu \mathrm{g} / \mathrm{L}$ per $10^{6}$ hepatocyte culture (Einarsson et al., 2000). An enzymatic immunoabsorbent assay generally has a concentration limit of 1-5 $\mu \mathrm{g} / \mathrm{L}$ BAs (Cell Biolabs Inc, 2017). Additionally, methods for extracting bile fluids from cultures are also quite limited. Bile extraction from harvested hepatocyte cultures is commonly performed to increase bile yield (Setchell et al., 1997; Ramaiahgari et al., 2014). However, these methods require hepatocyte extraction, often resulting in culture damage and shortening of the culture's age.

To date, liquid chromatography (LC)-mass spectrometry (MS) is widely utilized as an analytical method to quantify solutes in bile fluids. It has a rapid bile profiling and a detection limit of $10 \mathrm{ng} / \mathrm{L}$ (Perwaiz et al., 2001; Scherer et al., 2009), showing a higher precision of $5 \mathrm{ng} / \mathrm{L}$ for ultraperformance LC-MS (Sarafian et al., 2015). Another common method is to calculate the fraction of hepatocytes with and without the canaliculi network (Boyer, 2013). Both methods hardly allow direct quantification of the solutes secreted into the bile. Appropriate clearance is 
a preferable method that would provide direct secretion while preventing tissue extraction. It may also prolong the culture age, which is suitable for chronic models.

\section{IDEAL BILE PRODUCTION AND COLLECTION FOR IN VITRO LIVER TOXICITY ANALYSES}

Numerous studies have been performed to develop advanced bile fluids collection methods and enhance bile assays in vitro. These attempts included alterations in the culture model, integration with microtechnology, and bile recovery methods (see Figure 1, Table 1).

\section{Cell Source for Producing Bile}

Primary hepatocytes are the most ideal cell source to represent major liver functions. In both academia and the pharmaceutical industry, the utilization of primary human hepatocytes (PHHs) has been accepted as the gold standard to access human liver function (Hirano et al., 2004; Yamashiro et al., 2006; Maeda and Sugiyama, 2010; Izumi et al., 2017). Donor to donor variations in functions of PHHs can provide valuable information on individual differences in actual human population. However, we should pay attention to some drawbacks to the use of PHHs. In the process of cell preparation, the viability of prepared PHHs is largely dependent on individual batches (Levy et al., 2015; Ruo et al., 2020). Moreover, donor-to-donor variations in the in vitro functions of PHHs cannot always correspond to the individual differences in liver functions among actual human population since they come from not only intrinsic hepatic functional variations but other artifacts such as the different situations of cell isolation from donors (e.g., elapsed time from the death of donor to the isolation of PHHs, warm ischemic time, efficiency of collagenase perfusion in the liver) (Olinga et al., 1998; Shitara et al., 2003; Godoy et al., 2013). In academia, the variations could impair the reproducibility and reliability of results. Besides, the cost and limited availability of PHHs sometimes impose a burden on basic research. From this perspective, development of alternative cell sources has been an issue. The establishment of an oncostatin $\mathrm{M}$ (OSM)-dependent expansion of $\mathrm{PHH}$-overexpressed human papillomavirus (HPV) oncogenes increases the $\mathrm{PHH}$ availability for in vitro cultures. It expresses E6 and E7 oncogenes, which are responsible for hepatocyte immortality, as activated by OSM addition. The OSM addition stimulates the proliferation of $\mathrm{PHH}$ overexpressed HPV oncogenes up to 40 populations (doubling), whereas OSM removal results in proliferation and triggers differentiation into mature PHH (Levy et al., 2015). Several groups have reported the generation of chimeric mice with transplantation of human hepatocytes into immunodeficient mice [e.g., urokinase-type plasminogen activator/severe combined immunodeficiency (uPA/SCID) mice (Tateno et al., 2004), $\mathrm{Fah}^{-/-} / \mathrm{Rag}^{-/-} / \mathrm{Il} 2 \mathrm{rg}^{-/-}$mice (Azuma et al., 2007), and TK-NOG mice (Yamasaki et al., 2010)]. In these chimeric mice, large parts of the liver were replaced with transplanted human hepatocytes. The functions of isolated hepatocytes were reported to be comparable with PHHs (Nishimura et al., 2005). Additionally, these chimeric hepatocytes can be maintained with external oxygen supplies, hierarchical cocultures with 3T3 cells, or additions of ECM (Kimura et al., 2019). These studies increase the availability of fresh PHHs instead of cryopreserved cells.

The use of hepatocyte cell lines is also expected to be a suitable alternative to $\mathrm{PHH}$ for in vitro bile analyses. HepaRG is a bipotent cell line established from hepatocarcinoma that has been extensively utilized for cytochrome P450 (CYP) induction assays and bile analyses (Andersson et al., 2012; Takahashi et al., 2015; Woolbright and Jaeschke, 2015; Woolbright et al., 2015; Susukida et al., 2016). It demonstrates superior BA transport and drug metabolite disposition, as opposed to other common hepatic cell lines (e.g., HepG2) (Takahashi et al., 2015; Woolbright and Jaeschke, 2015; Ni et al., 2016; Susukida et al., 2016; Penman et al., 2019). It also exhibits a similar response to the relevant dose of BA-induced toxicity as PHH (Woolbright et al., 2015). An evaluation of bile metabolites using HepaRG demonstrated that the influx and efflux bile transporters were properly distributed to apical (BSEP, MRP2, MDR1, MDR3) or basolateral (NTCP, MRP3) sites. However, in comparison to $\mathrm{PHHs}$, there are some drawbacks that need to be considered. First, the cost of HepaRG cells per vial is comparable to PHHs. Second, some BA transporter expressions, such as BSEP and NTCP, and the amount of bile secretion in HepaRG were still less compared to that of PHH (Bachour-El Azzi et al., 2015). In addition, some drugmetabolizing enzymes, such as CYP1A2, CYP2A6, and CYP2D6, were reported to have a significantly lower level of expression in HepaRG cells than in PHHs (Andersson et al., 2012). Third, as is true with all cell lines, it is derived from a single donor and thus not suitable to assess the effect of diverse genetic background in actual human population.

Additionally, protocols for liver-cell differentiation have been widely established (Si-Tayeb et al., 2010; Miyajima et al., 2014). Human-induced pluripotent stem cell (iPSC)-derived hepatocytes (hiHeps) are genetically more closely related to $\mathrm{PHH}$ than are hepatoma cell lines (Gao and Liu, 2017). The hiHeps have demonstrated the capacity for bile production in sandwich culture, as shown by total BA syntheses and responses toward hepatoprotective substances (Ni et al., 2016). Regardless of the transcriptomic study conducted (Gao and Liu, 2017), hiHeps still exhibit inferior drug metabolic properties compared with HepaRG (Kvist et al., 2018). An in vitro experiment validated that hiHeps possess lowered CYP protein, particularly CYP7A1, which decreased the amount of total BA by $30 \% \mathrm{PHH}$ (Ni et al., 2016). Additionally, it expressed low BSEP activities as opposed to MRP2 (Sakai et al., 2019). Thus, optimum modulation of iPSC differentiation toward liver cells is necessary, considering that hiHeps has a high potential for bile testing.

\section{Modulation in Tissue-Culture Method}

Methods for culturing liver tissue have been known to create an ideal environment to support liver-cell physiology, including bile production. Such bile production can be sustained through the maintenance of bile canaliculi between adjacent hepatocytes where bile is first secreted. One approach maintains the oxygen supplies toward culture system to 
A

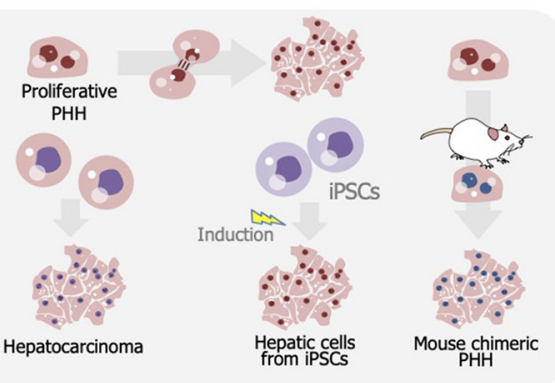

B

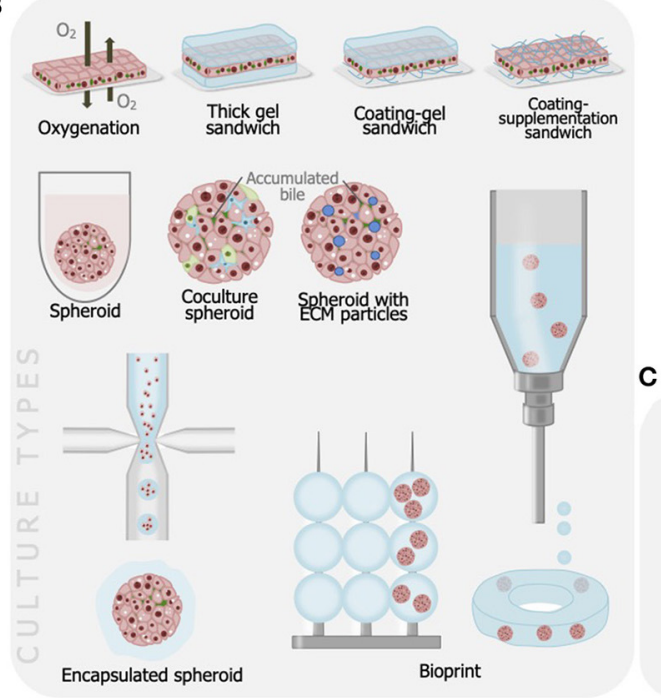

C
E

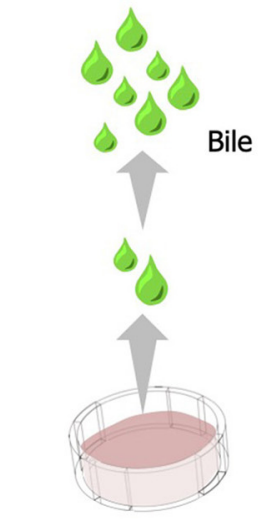

In vitro system

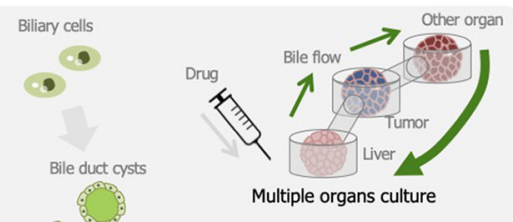

20

Multiple organs cultur
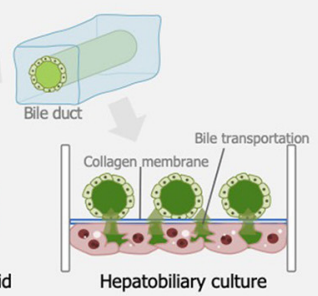

Hepatobiliary organoid

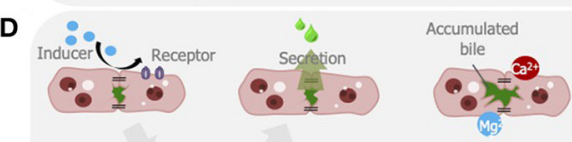

0 bile inducement
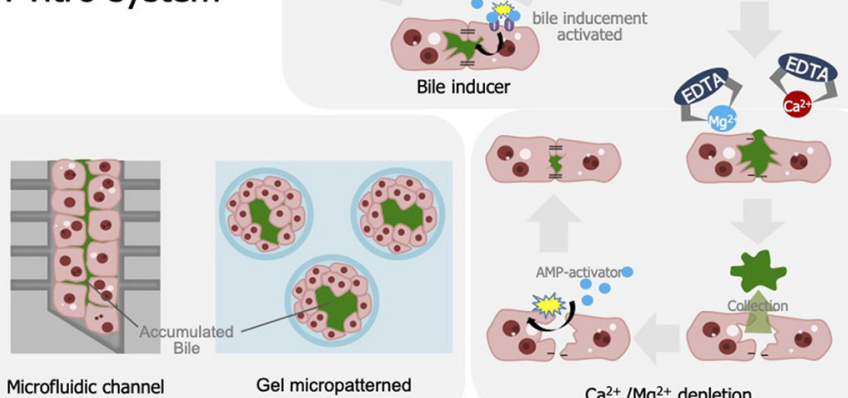

$\mathrm{Ca}^{2+} / \mathrm{Mg}^{2+}$ depletion

FIGURE 1 | Strategies developed for improving bile production and recovery for liver cell-based assay including (A) utilization of various cell sources for optimum bile production; (B) modulation of culture model that is efficient for bile secretion and production; (C) integration with microfabrication, modulation of bile production, and recovery methods using (D) agents and chelates; and (E) integration of liver tissues to enable autologous bile recovery.

support high hepatocyte metabolism rates (Giglioni et al., 2018). Hepatocyte culture has been established on oxygenpermeable polydimethylsiloxane to maintain hepatocyte bile canaliculi. This culture model exhibits favorable morphology and function of hepatocytes over hepatocyte cultures on polystyrene surfaces (Matsui et al., 2010; Xiao et al., 2014, 2015). Additionally, continuous direct oxygenation can be achieved using a collagen Vitrigel membrane chamber (Oshikata-Miyazaki and Takezawa, 2016). Hepatocyte cultures have shown active bile-conjugate secretion into both bile canaliculi networks and extracellular solutions.

Extracellular matrices (ECMs) have been shown to maintain bile canaliculi. Sandwich configurations have been thoroughly explored to reestablish the specific transporters on the canalicular and sinusoidal membrane domains significant for bile-based analyses (Levy et al., 2015; Yang et al., 2017). They employ various kinds of ECM proteins, including collagen (Swift et al., 2010; Chatterjee et al., 2014; Keemink et al., 2015; Deharde et al., 2016; Zeigerer et al., 2017), Matrigel (Deharde et al., 2016; Sun et al., 2019), laminin (Watanabe et al., 2016), or combinations (Swift et al., 2010; Marion et al., 2012; Fukuda et al., 2014; Keemink et al., 2015; Xiao et al., 2015; Deharde et al., 2016; Ni et al., 2016;
Susukida et al., 2016; Ogimura et al., 2017). Notably, distinct ECM compositions, including layering, have had diverse impacts on liver culture. The cellular arrangement and morphology of liver cells are mainly governed by underlay ECM, whereas the canalicular network and bile secretions are affected by the overlay ECM (Deharde et al., 2016). A combination of collagen underlayMatrigel overlay appears to be the ideal sandwich mixture needed to simulate a hepatocyte architecture and functions related to bile production. These sandwich cultures can preserve the optimum bile canaliculi network and CYP1A1/2 activity for 1 week while maintaining the culture for 2 weeks (Xiao et al., 2015; Lauschke et al., 2016). This culture model is flexible and can be combined with other culture modifications, owing to its simplicity.

A self-organized three-dimensional model in a spheroid configuration successfully improved bile production and toxicity assays. Spheroids increase cell density, cell-contact polarity, and culture plasticity, including coculture modulation and ECM inclusion (Soldatow et al., 2013; Ramaiahgari et al., 2014; Fatehullah et al., 2016). Unlike sandwich configurations, liver cultures in spheroid configurations allow multiple canalicular sites, thus maintaining superior phase I and II enzyme activities (Soldatow et al., 2013; Ramaiahgari et al., 2014) with a culture age 
TABLE 1 | Recent studies that significant on the advancement of bile production and collection from liver in vitro model.

\begin{tabular}{|c|c|c|c|c|c|c|c|}
\hline Target of modulation & Type of modulation & $\begin{array}{l}\text { Ideal design for bile production and } \\
\text { collection }\end{array}$ & Organism/s & $\begin{array}{l}\text { Degree of } \\
\text { modulation }\end{array}$ & $\begin{array}{l}\text { Bile amount } \\
\text { collected }\end{array}$ & $\begin{array}{l}\text { Relevancy for bile } \\
\text { fluids collection }\end{array}$ & References \\
\hline \multirow[t]{3}{*}{ Cell source } & $\begin{array}{l}\text { Long-term primary } \\
\text { hepatocytes }\end{array}$ & $\begin{array}{l}\text { OSM-dependent human primary } \\
\text { hepatocytes, human hepatocyte-chimeric } \\
\text { mice }\end{array}$ & Human, mouse & Moderate-high & Low-high a,b,c & High & $\begin{array}{l}\text { Tateno et al., 2004; Nishimura } \\
\text { et al., 2005; Azuma et al., 2007; } \\
\text { Yamasaki et al., 2010; Levy } \\
\text { et al., 2015; Kimura et al., 2019; } \\
\text { Ruo et al., } 2020\end{array}$ \\
\hline & Hepatocytes cell line & HepaRG & & Low & Low-high ${ }^{a, b, c}$ & Moderate-High & $\begin{array}{l}\text { Andersson et al., 2012; } \\
\text { Bachour-El Azzi et al., 2015; } \\
\text { Takahashi et al., 2015; } \\
\text { Woolbright and Jaeschke, 2015; } \\
\text { Woolbright et al., 2015; } \\
\text { Susukida et al., } 2016\end{array}$ \\
\hline & iPSCs-derived cells & hiHeps & & Moderate-High & Low-Moderate ${ }^{b}$ & $\begin{array}{l}\text { Moderate- } \\
\text { Potentially } \\
\text { high }\end{array}$ & $\begin{array}{l}\text { Ni et al., 2016; Kvist et al., 2018; } \\
\text { Sakai et al., } 2019\end{array}$ \\
\hline \multirow[t]{3}{*}{ Culture design } & Oxygenated culture & $\begin{array}{l}\text { PDMS permeable membrane, Vitrigel } \\
\text { membrane }\end{array}$ & Human, rat & Low $^{c, b}$ & Moderate-High & Moderate-High & $\begin{array}{l}\text { Matsui et al., 2010; Xiao et al., } \\
\text { 2014, 2015; Oshikata-Miyazaki } \\
\text { and Takezawa, } 2016\end{array}$ \\
\hline & Sandwich culture & $\begin{array}{l}\text { Collagen-Matrigel sandwich (thick gel and } \\
\text { supplementation) }\end{array}$ & $\begin{array}{l}\text { Human, rat, } \\
\text { mouse }\end{array}$ & Low $^{a}$ & Moderate-High & Moderate-High & $\begin{array}{l}\text { Swift et al., 2010; Marion et al., } \\
\text { 2012; Chatterjee et al., 2014; } \\
\text { Fukuda et al., 2014; Keemink } \\
\text { et al., 2015; Xiao et al., 2015; } \\
\text { Deharde et al., 2016; Lauschke } \\
\text { et al., 2016; Ni et al., 2016; } \\
\text { Susukida et al., 2016; Watanabe } \\
\text { et al., 2016; Ogimura et al., } \\
\text { 2017; Yang et al., 2017; Zeigerer } \\
\text { et al., 2017; Sun et al., 2019; } \\
\text { Ruo et al., } 2020\end{array}$ \\
\hline & 3D spheroid & $\begin{array}{l}\text { Coculture of 3D spheroid, liver } \\
\text { organoid, spheroid encapsulation, } \\
\text { and bioprinting }\end{array}$ & & Low-Moderate ${ }^{a}$ & Moderate-High & Moderate-High & $\begin{array}{l}\text { Tamai et al., 2013; Astashkina } \\
\text { and Grainger, 2014; Rebelo } \\
\text { et al., 2015; Takahashi et al., } \\
\text { 2015; Ware et al., 2015; Yamada } \\
\text { et al., 2015; Bells et al., 2016; } \\
\text { Chan et al., 2016; Lauschke } \\
\text { et al., 2016; Ni et al., 2016; } \\
\text { Ahmed et al., 2017; Kizawa } \\
\text { et al., 2017; Vorrink et al., 2017; } \\
\text { Baze et al., 2018; Underhills and } \\
\text { Khetani, 2018; Fiorotto et al., } \\
2019\end{array}$ \\
\hline
\end{tabular}


TABLE 1 | Continued

Multi-tissue interactions Development of bile duct structure

Addition of $\mathrm{PGE}_{2}$

Micropattern cyst-tube making, bile duct differentiation, bile duct in vitro morphogenesis

Hepatobilary model

Hepatobiliary spheroid, collagen membrane, ECM-based scaffold

Integrated multiorgans system

Direct collection of bile

${ }^{a}$ Combined with oxygenation.

${ }^{b}$ Combined with organoid culture.

${ }^{c}$ Often combined with sandwich culture.

${ }^{d}$ Combined with micropattern or microfluidics.

*Bile salts directly transported and affect the organ of interest.

Oil injector
Ideal design for bile production and Organism/s

\section{Degree of}

Bile amount

collected

Relevancy for bile References

fluids collection

Moderate-High ${ }^{\mathrm{b}, \mathrm{d}}$

Potentially

moderate-High

Potentially

moderate-High

Moderate-High

Matsui et al., 2012

$\mathrm{High}^{\mathrm{C}}$

Moderate-

Potentially

high

Human, rat

Low-Moderate $\mathrm{a}^{\mathrm{a}, \mathrm{c}}$

Moderate-High

Moderate-High

Nakao et al., 2011; Wang et al., 2018

Swift et al., 2010; Marion et al. 2012; Fukuda et al., 2014;

Bachour-El Azzi et al., 2015; Ni

et al., 2016: Yang et al., 2016:

Yan et al., 2017; Ying et al., 2018

Fu et al., 2010; Brouwer et al.,

2013

$\begin{array}{lll} & \text { Poderate } & \\ & \text { moderate-High } & \text { Moderate }\end{array}$

$H_{i g h}^{a, c, d}$

Potentially high

Potentially high

mouse

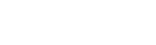

Tanimizu et al., 2007, 2012; Kido et al., 2015; Sampaziotis et al., 2015; Miura et al., 2018;

Rizki-Safitri et al., 2018, 2020;

Funfak et al., 2019; Du et al.

2020; Hafiz et al., 2021

Human, rat Moderate- Potentially high Potentially high Katsuda et al., 2013; Vyas et al.,

2018; Wu et al., 2019

High $^{\mathrm{d}} \quad-^{\star} \quad$ Potentially high

Maschmeyer et al., 2015; Chen et al., 2017; Choe et al., 2017;

Skardal et al., 2020

Rat

$\mathrm{High}^{\mathrm{d}}$

Moderate-High

Matsui et al., 2012 
of up to 5 weeks (Bells et al., 2016; Lauschke et al., 2016). Liver spheroids have been reported to amplify drug metabolism and bile-related performances of various cell sources, including PHH (Vorrink et al., 2017), HepaRG (Sun et al., 2019), HepG2 (Tamai et al., 2013; Yamada et al., 2015), and hiHeps as liver organoids (Lauschke et al., 2016; Ni et al., 2016; Fiorotto et al., 2019). It can also enhance BSEP expression in HepaRG cells (Sun et al., 2019). A study using 56 endogenous compounds demonstrated a 3-week stability of endogenous and xenobiotic metabolites in the $\mathrm{PHH}$ spheroid. Notably, the BA composition excreted by the PHH spheroid contained higher glycine-conjugated BA compared with freshly isolated PHH (Vorrink et al., 2017). Cocultures with liver non-parenchymal cells, such as fibroblasts (Tamai et al., 2013; Ware et al., 2015; Underhills and Khetani, 2018), Kupfer cells, bile duct cells, and stellate cells (Bells et al., 2016; Baze et al., 2018; Underhills and Khetani, 2018) stabilize the PHH function. They also support the PHH culture for long-term exposure toxicity tests. These cocultures displayed a three-fold higher BA accumulation as a response to chlorpromazine in cholestatic presence (Bells et al., 2016).

Although liver spheroids display merits for in vitro liver cultures, the model has several limitations. First, the greater the size and density of the liver spheroid, the more susceptible it is to necrotic core development (Astashkina and Grainger, 2014). Only spheroids having diameters of $\sim 200 \mu \mathrm{m}$ (1.5-2 $\times 10^{3}$ cells/spheroids) receive adequate oxygenation that can reach the spheroid core (Bells et al., 2016; Ahmed et al., 2017). ECM incorporation of spheroid collagen fibrils (Tamai et al., 2013), collagen microparticles (Ahmed et al., 2017), encapsulations (Rebelo et al., 2015; Chan et al., 2016), and bioprinting techniques (Kizawa et al., 2017) have reportedly permitted greater oxygenation. The BA production increases two-fold on day 4 from the prior day in PHHs (Kizawa et al., 2017). Second, liver spheroids possess multiple canalicular networks, yet they serve as a close system for bile fluids collection. A micropatterned collagen gel can organize liver aggregates in their spheroid formation while sustaining their metabolic function. Notably, these spheroids have an enlarged bile canaliculi site that is openly exposed to the culture medium, enabling direct bile fluids collection. The bile canaliculus accumulates a bile analog that is successfully recovered using an oil injector. The quantity of recovered bile is $27 \times$ greater than that of the sandwich culture (Matsui et al., 2012). Based on this study, the presence of an outlet that feasibly extends the canalicular network can realize the bile fluids collection in vitro.

A dynamic culture liver model employing microfluidic technology (Nakao et al., 2011; Zhou et al., 2015; Haque et al., 2016; Wang et al., 2018) has drawn attention for bile canaliculi and as a bile outlet establishment. A sinusoidal-like fluidic chamber effectively aligns hepatocytes and controls the bile canaliculi formation corresponding to the hepatic cord structure (Nakao et al., 2011). Furthermore, the microfluidic platform enhances the maturation of hiHeps organoids (Wang et al., 2018). Although it has not been demonstrated, this system can feasibly provide continuous bile fluids collected from the chamber outlet.

\section{Utilization of Inducing Agent for Bile Secretion and Opening of Bile Canaliculus}

Manipulating the gradient concentration in a culture medium can facilitate the bile outlet from a canalicular network. A gradient difference generated by $\mathrm{Ca}^{2+} / \mathrm{Mg}^{2+}$ stimulates the bile canaliculi opening to release bile into the culture medium. A well-established method is the B-Clear ${ }^{\circledR}$ technology. This technology has been broadly used to calculate bile excretion and accumulation from hepatocyte sandwich cultures (Marion et al., 2012; Fukuda et al., 2014; Bachour-El Azzi et al., 2015; Ni et al., 2016; Yan et al., 2017). This method creates a $\mathrm{Ca}^{2+}$ or $\mathrm{Mg}^{2+}$ concentration difference between the hepatocyte culture and the culture medium, and the depletion disrupts the bile canaliculi tight junction. It involves the utilization of Hank's balanced salt solution as a carrier buffer of $\mathrm{Ca}^{2+} / \mathrm{Mg}^{2+}$. A bile fraction collected from the disrupted bile canaliculi is obtained from the accumulation difference between buffer $\mathrm{Ca}^{2+} / \mathrm{Mg}^{2+}$ and buffer-free $\mathrm{Ca}^{2+} / \mathrm{Mg}^{2+}$, as presented by the biliary excretion index (BEI). This method can also be used to assess the basolateral and canalicular efflux of bile and the substance of interest by measuring the mass difference in the absence and presence of $\mathrm{Ca}^{2+} / \mathrm{Mg}^{2+}$ (Swift et al., 2010; Ying et al., 2018). A long-term $\mathrm{Ca}^{2+} / \mathrm{Mg}^{2+}$ incubation may lead to cell toxicity and irreversible bile canaliculi disruption. Postclearance treatment using AMP-activated protein kinase activators (e.g., 2-deoxyglucose, 5-aminoimidazole-4-carboxamide-1-b-riboside, metformin, and forskolin) can induce hepatocyte tissue retention while maintaining the bile canaliculi network (Ying et al., 2018). This treatment increases the applicability of longterm hepatocyte cultures with regular bile clearance. To maximize bile secretion, bile inducers or chelates can be utilized to alter bile production. Prostaglandin $\mathrm{E}_{2}\left(\mathrm{PGE}_{2}\right)$ is a lipid inflammatory mediator that potentially enhances bile production. The deficiency of $\mathrm{PGE}_{2}$ receptor subtype 3 (EP3) and 4 (EP4) downregulates the expression of CYP7A1, resulting in inhibition of BA synthesis and hypercholesterolemia (Fu et al., 2010; Brouwer et al., 2013).

The BEI determination appears to be the most convenient approach to predicting bile secretion in vitro. Nonetheless, this value depends on the amount associated with hepatocytes. Furthermore, the adequacy of solutes concentration in the bile canaliculi to draw water flow, which also acts as a driving force, remains unclear. Under such conditions, drug concentrations with or without bile canaliculi must be determined to estimate the amount of bile solutes secreted into the bile canaliculi.

\section{Integration of Multiple Tissues for Bile Transportation}

In addition to the bile accumulation in canaliculi, multiple liver tissues (e.g., bile duct) and other organs (e.g., intestine) convey bile prior to their excretion from the body. These tissues and organs are also responsible for the modification of bile components, including the transformation of primary bile into secondary bile by gut-resided microbiomes (Ridlon et al., 2014; Quinn et al., 2020). The bile duct is a liver tissue that 
exclusively regulates the accumulation and transportation of bile inside the liver, and it consists of intra- and extrahepatic biliary ducts (Lemaigree, 2009; Boyer, 2013; Chiang, 2013; Han et al., 2013; Matsui et al., 2018). The inclusion of a bile duct in vitro not only demonstrates the hepatobiliary interaction, but it also suggests bile recovery outlet from the liver culture.

Hepatobiliary organoids established from liver progenitor cells using multiple apparatuses [e.g., decellularized liver scaffolds, U-bottom plates, and coated plates (Katsuda et al., 2013; Vyas et al., 2018; Wu et al., 2019)] are promising for physiologically collecting bile from hepatocytes. A study demonstrated bile accumulation in the bile duct sac/cyst that was situated in the organoid core (Katsuda et al., 2013). Nonetheless, the location of the bile duct in this organoid makes bile fluids collection difficult. The development of bileduct organization is potentially instrumental in resolving this hindrance. Some studies have demonstrated that the bile duct can be independently reconstructed in vitro. Microstructures and scaffold gels are effective for spatially controlling biliary cells to form functional bile-duct cysts (Miura et al., 2018; Rizki-Safitri et al., 2018; Funfak et al., 2019) and tubes (Du et al., 2020) using cells from rodents. These biliary structures express active bile transporters under a rich-laminin ECM environment. Laminin is essential for bile duct polarity and is thus frequently utilized for bile-duct development from iPSCs (Tanimizu et al., 2007, 2012; Kido et al., 2015; Sampaziotis et al., 2015). Attempts to integrate hepatobiliary cultures have demonstrated the transportation of bile conjugates from hepatocytes to the bile-duct structure. Liver spheroids comprising hepatocytes, biliary cells, and fibroblasts have had biliary cyst structures on their periphery. The structures developed into duct-like structures that connected liver spheroids while possibly transporting the bile conjugate (Hafiz et al., 2021). A collagen culture insert has demonstrated the likelihood of transporting bile conjugate from the hepatocyte to the bile-duct structure (Rizki-Safitri et al., 2020). The referred study showed the potential of separate autologous bile clearances suitable for long-term toxicity testing. Although bile-duct inclusion is promising for bile fluids collection in vitro, independent bileduct structures are unable when demonstrating hepatobiliary bile fluids transportation. The bile-duct function has always been associated with bile canaliculus in adjacent hepatocytes. Furthermore, bile ducts in vitro remain immature. Thus, they are unlikely to perform optimum bile fluids collection. The technique for integrating hepatobiliary using membranes also diminishes direct hepatobiliary contact, resulting in bile leakage.

A multitissue/organ culture that incorporates liver tissue with other organs might simplify the recovery process. In addition to the blood stream, the intestine is the subsequent organ where bile is disembogued and experiences further modification (Boyer, 2013; Chiang, 2013). A microfluidic liver-intestine platform can demonstrate relations between biological processes in the liver and intestine, including processes related to bile production and secretion (Maschmeyer et al., 2015; Chen et al., 2017; Choe et al., 2017). This system allows the direct impact of bile, particularly in demonstrating interorgan drug-dependence studies. However, considering that the intestine displays twoway interactions with the liver, these intestine-liver platforms focus on drug absorption in the digestive tract instead of vice versa. Additionally, an integrated platform that combines organoids from six organs demonstrates the alteration of liver metabolites using human-relevant dose drug dependence. This system exhibits the activation of a prodrug into an active drug that rarely occurs in the absence of liver organoids. Analyses of the liver organoid metabolite displays the presence of 5fluorouracyl, which is a product of capecitabine metabolism by the liver. 5-Fluorouracyl is highly toxic and destructive to heart and lung organoids as downstream organs in a microfluidic platform (Skardal et al., 2020). Little is known about the bile composition and whether this metabolite is toxic specifically toward the heart and lung or merely to adjacent tissues/organs.

\section{CONCLUSION/OUTLOOK}

Bile assays may offer numerous advantages to complement standard in vitro liver function analyses. Recent studies have shown that the liver-culture model enables in vitro bile production and collection. In vitro bile fluids collection can be potentially used as a supportive assay in the liver model. It can also be used to understand drug effects and secretion processes. The available bile fluids collection model exhibits flexibility toward modulations and integration with technologies, such as microfluidic devices. It allows an integrated liver tissue that is promising for recreating multitissue organization, which is advantageous for in vitro bile fluids collection and clearance. We know that not all types of cells or technology are desirable for bile analyses. Hence, the determination of appropriate culture modulations will increase the efficiency and appositeness of in vitro bile analyses. Altogether, complex liver tissue is substantial in establishing a relevant in vitro liver applicable for broader preclinical assays.

\section{AUTHOR CONTRIBUTIONS}

AR-S and YS conceived the review. AR-S, FT, and MN drafted the manuscript. AR-S and FT generated the figure and table. AR-S, FT, MN, MT, KM, HK, and YS critically revised the manuscript. All authors contributed to the article and approved the submitted version.

\section{FUNDING}

We would like to thank Japan Agency for Medical Research and Development (AMED) 2017-2021 (grant number: 20be0304201h0004) for the funding.

\section{ACKNOWLEDGMENTS}

We would like to thank Editage (www.editage.com) and Avery Morrow for English language editing. 


\section{REFERENCES}

Ahmed, H., Salerno, S., Piscioneri, A., Khakpour, S., Giorno, L., and De Bartolo, L. (2017). Human liver microtissue spheroids in hollow fiber membrane bioreactor. Colloid Surface B Biointerfaces 160, 272-280. doi: 10.1016/j.colsurfb.2017.09.024

Almazroo, O. A., Miah, M. K., and Venkataramanan, R. (2017). Drug metabolism in the liver. Clin. Liver Dis. 21, 1-20. doi: 10.1016/j.cld.2016.08.001

Andersson, T. B., Kanebratt, K. P., and Kenna, J. G. (2012), The HepaRG cell line: a unique in vitro tool for understanding drug metabolism and toxicity in human. Expert Opin. Drug Metab. Toxicol. 8, 909-920. doi: 10.1517/17425255.2012.685159

Astashkina, A., and Grainger, D. W. (2014). Critical analysis of 3-D organoid in vitro cell culture models for high-throughput drug candidate toxicity assessments. Adv. Drug Deliv. Rev. 69-70, 1-18. doi: 10.1016/j.addr.2014.02.008

Azuma, H., Paulk, N., Ranade, A., Dorrell, C., Al-Dhalimy, M., Ellis, E., et al. (2007). Robust expansion of human hepatocytes in Fah-/-/Rag2-/-/Il2rg-/mice. Nat. Biotechnol. 25, 903-910. doi: 10.1038/nbt1326

Bachour-El Azzi, P., Sharanek, A., Burban, A., Li, R., Guével, R. L., Abdel-Razzak, Z., et al. (2015). Comparative localization and functional activity of the main hepatobiliary transporters in HepaRG cells and primary human hepatocytes. Toxicol. Sci. 145, 157-168. doi: 10.1093/toxsci/kfv041

Barré-Sinoussi, F., and Montagutelli, X. (2015). Animal models are essential to biological research: issues and perspectives. Future Sci. OA 1:FSO63. doi: $10.4155 /$ fso. 15.63

Bathena, S. P., Thakare, R., Gautam, N., Mukherjee, S., Olivera, M., Meza, J., et al. (2015). Urinary bile acids as biomarkers for liver diseases I. Stability of the baseline profile in healthy subjects. Toxicol. Sci. 143, 296-307. doi: $10.1093 /$ toxsci/kfu227

Baze, A., Parmentier, C., Hendriks, D., Hurrell, T., Heyd, B., Bachellier, P., et al. (2018). 3D-spheroid primary human hepatocytes in mono- and coculture with non-parenchymal cells. Tissue Eng. Part C ME 9, 534-545. doi: 10.1089/ten.tec.2018.0134

Bells, C. C., Hendriks, D. F., Moro, S. M., Ellis, E., Walsh, J., Renblom, A., et al. (2016). Characterization of primary human hepatocyte spheroids as a model system for drug-induced liver injury, liver function and disease. Sci. Rep. 6:25187. doi: 10.1038/srep25187

Bloomer, J. C., Nash, M., Webb, A., Miller, B. E., Lazaar, A. L., Beaumont, C., et al. (2013). Assessment of potential drug interactions by characterization of human drug metabolism pathways using non-invasive bile sampling. Br. J. Clin. Pharmacol. 75, 488-496. doi: 10.1111/j.1365-2125.2012.04 352.x

Boyer, J. L. (2013). Bile formation and secretion. Compr. Physiol. 3, 1035-1078. doi: $10.1002 /$ cphy.c120027

Brouwer, K. L., Keppler, D., Hoffmaster, K. A., Bow, D. A., Cheng, Y., Lai, Y., et al. (2013). In vitro methods to support transporter evaluation in drug discovery and development. Clin. Pharmacol. Ther. 94, 95-112. doi: 10.1038/clpt.2013.81

Cell Biolabs Inc (2017). Total Bile Acid Assay Kit: Product Manual. Available online at: www.cellbiolabs.com/sites/default/files/ STA-631-total-bile-acid-assay-kit.pdf (accessed June 3, 2019).

Chan, H. F., Zhang, Y., and Leong, K. W. (2016). Efficient one-step production of microencapsulated hepatocyte spheroids with enhanced functions. Small 12, 2720-2730. doi: 10.1002/smll.201502932

Chatterjee, S., Bijsmans, I. T., van Mil, S. W., Augustijns, P., and Annaert, P. (2014). Toxicity and intracellular accumulation of bile acids in sandwichcultured rat hepatocytes: Role of glycine conjugates. Toxicol. Vitro 28, 218-230. doi: 10.1016/j.tiv.2013.10.020

Chen, W., Edington, C., Suter, E., Yu, J., Velazquez, J. J., Velazquez, J. G., et al. (2017). Integrated gut/liver microphysiological systems elucidates inflammatory inter-tissue crosstalk. Biotechnol. Bioeng. 114, 2648-2659. doi: 10.1002/bit.26370

Chiang, J. Y. (2013). Bile acid metabolism and signaling. Compr. Physiol. 3, 1191-1212. doi: 10.1002/cphy.c120023

Choe, A., Ha, S. K., Choi, I., Choi, N., and Sung, J. H. (2017). Microfluidic gutliver chip for reproducing the first pass metabolism. Biomed. Microdevices 19:4. doi: 10.1007/s10544-016-0143-2
Deharde, D., Schneider, C., Hiller, T., Fischer, N., Kegel, V., Lübberstedt, M., et al. (2016). Bile canaliculi formation and biliary transport in 3D sandwichcultured hepatocytes in dependence of the extracellular matrix composition. Arch. Toxicol. 90, 2497-2511. doi: 10.1007/s00204-016-1758-Z

Du, Y., Khandekar, G., Llewellyn, J., Polacheck, W., Chen, C. S., and Wells, R. G. (2020). A bile duct-on-a-chip with organ-level functions. Hepatology 71, 1350-1363. doi: 10.1002/hep.30918

Einarsson, C., Ellis, E., Abrahamsson, A., Ericzon, B. G., Bjorkhem, I., and Axelson, M. (2000). Bile acid formation in primary human hepatocytes. World J. Gastroenterol. 6, 522-525. doi: 10.3748/wjg.v6.i4.522

Fatehullah, A., Tan, S. H., and Barker, N. (2016). Organoids as an in vitro model of human development and disease. Nat. Cell Biol. 18, 246-254. doi: $10.1038 /$ ncb3312

Fiorotto, R., Amenduni, M., Mariotti, V., Fabris, L., Spirli, C., and Strazzabosco, M. (2019). Liver diseases in the dish: iPSC and organoids as a new approach to modeling liver diseases. BBA Mol. Basis Dis. 1865, 920-928. doi: 10.1016/j.bbadis.2018.08.038

Fu, D., Wakabayashi, Y., Ido, Y., Lippincott-Schwartz, J., and Arias, I. M. (2010). Regulation of bile canalicular network formation and maintenance by AMP-activated protein kinase and LKB1. J. Cell Sci. 123, 3294-3302. doi: $10.1242 /$ jcs.068098

Fukuda, H., Nakanishi, T., and Tamai, I. (2014). More relevant prediction for in vivo drug interaction of candesartan cilexetil on hepatic bile acid transporter bsep using sandwich-cultured hepatocytes. Drug Metab. Pharmacokinet. 29, 94-96. doi: 10.2133/dmpk.DMPK-13-NT-049

Funfak, A., Bouzhir, L., Gontran, E., Minier, N., Dupuis-Williams, P., and Gobaa, S. (2019). Biophysical control of bile duct epithelial morphogenesis in natural and synthetic scaffolds. Front. Bioeng. Biotechnol. 7:417. doi: 10.3389/fbioe.2019.00417

Funk, C., Ponelle, C., Scheuermann, G., and Pantze, M. (2001). Cholestatic potential of troglitazone as a possible factor contributing to troglitazoneinduced hepatotoxicity: in vivo and in vitro interaction at the canalicular bile salt export pump (Bsep) in the rat. Mol. Pharmacol. 59, 627-635. doi: $10.1124 / \mathrm{mol} .59 .3 .627$

Gao, X., and Liu, Y. (2017). A transcriptomic study suggesting human iPSC-derived hepatocytes potentially offer a better in vitro model of hepatotoxicity than most hepatoma cell lines. Cell Biol. Toxicol. 33, 407-421. doi: 10.1007/s10565-017-9383-z

Ghibellini, G., Leslie, E. M., and Brouwer, K. L. (2006). Methods to evaluate biliary excretion of drugs in humans: an updated review. Mol. Pharm. 3, 198-211. doi: $10.1021 / \mathrm{mp} 060011 \mathrm{k}$

Giglioni, E. H., Chang, J. C., Duijst, S., Go, S., Adam, A., Hoekstra, R., et al. (2018). Improved oxygenation dramatically alters metabolism and gene expression in cultured primary mouse hepatocytes. Hepatol Commun 2: 299-312. doi: 10.1002/hep4.1140

Godoy, P., Hewitt, N. J., Albrecht, U., Andersen, M. E., Ansari, N., Bhattacharya, S., et al. (2013). Recent advances in $2 \mathrm{D}$ and $3 \mathrm{D}$ in vitro systems using primary hepatocytes, alternative hepatocyte sources and non-parenchymal liver cells and their use in investigating mechanisms of hepatotoxicity, cell signaling and ADME. Arch. Toxicol. 87, 1315-1530. doi: 10.1007/s00204-013-1078-5

Griffiths, W. J., and Sjövall, J. (2010). Bile acids: analysis in biological fluids and tissues. J. Lipid Res. 51, 23-41. doi: 10.1194/jlr.R001941

Hafiz, E., Bulutoglu, B., Mansy, S. S., Chen, Y., Abu-Taleb, H., Soliman, S., et al. (2021). Development of liver microtissues with functional biliary ductular network. Biotechnol. Bioeng. 118, 17-29. doi: 10.1002/bit.27546

Han, Y., Glaser, S., Meng, F., Francis, H., Marzioni, M., McDaniel, K., et al. (2013). Recent advances in the morphological and functional heterogeneity of the biliary epithelium. Exp. Biol. Med. 28, 549-565. doi: $10.1177 / 1535370213489926$

Haque, A., Gheibi, P., Stybayeva, G., Gao, Y., Torok, N., and Revzin, A. (2016). Ductular reaction-on-a-chip: Microfluidic co-cultures to study stem cell fate selection during liver injury. Sci. Rep. 6:36077. doi: 10.1038/srep36077

Hirano, M., Maeda, K., Shitara, Y., and Sugiyama, Y. (2004). Contribution of OATP2 (OATP1B1) and OATP8 (OATP1B3) to the hepatic uptake of pitavastatin in humans. J. Pharmacol. Exp. Ther. 311, 139-146. doi: 10.1124 /jpet.104.068056 
Hofmann, A. F., and Hagey, L. R. (2014). Bile acid chemistry, biology, and therapeutics during the last 80 years: historical aspects. J. Lipid Res. 55, 1553-1595. doi: 10.1194/jlr.R049437

Hughes, J. P., Rees, S., Kalindjian, S. B., and Philpott, K. L. (2011). Principles of early drug discovery. Br. J. Pharmacol. 162, 1239-1249. doi: 10.1111/j.1476-5381.2010.01127.x

Izumi, S., Nozaki, Y., Komori, T., Takenaka, O., Maeda, K., Kusuhara, H., et al. (2017). Comparison of the predictability of human hepatic clearance for organic anion transporting polypeptide substrate drugs between different in vitro-in vivo extrapolation approaches. J. Pharm. Sci. 106, 2678-2687. doi: 10.1016/j.xphs.2017.02.012

Katsuda, T., Kojima, N., Ochiya, T., and Sakai, Y. (2013). Biliary epithelial cells play an essential role in the reconstruction of hepatic tissue with a functional bile ductular network. Tissue Eng Part A 19: 2402-2411. doi: 10.1089/ten.tea.2013.0021

Keemink, J., Oorts, M., and Annaert, P. (2015). "Primary hepatocytes in sandwich culture," in Protocols in In Vitro Hepatocyte Research, Methods in Molecular Biology, eds M. Vinken, and V. Rogiers, Vol. 1250 (New York, NY: Springer Science+Business Media), 363-376.

Kemp, D. C., and Brouwer, K. L. (2004). Viability assessment in sandwichcultured rat hepatocytes after xenobiotic exposure. Toxicol. Vitro 18, 869-877. doi: 10.1016/j.tiv.2004.04.014

Kido, T., Koui, Y., Suzuki, K., Kobayashi, A., Miura, Y., Chern, E. Y., et al. (2015). CPM is a useful cell surface marker to isolate expandable bi-potential liver progenitor cells derived from human iPS cells. Stem Cell Rep. 5, 508-515. doi: 10.1016/j.stemcr.2015.08.008

Kimura, K., Horiguchi, I., Kido, T., Miyajima, A., and Sakai, Y. (2019). Enhanced hepatic differentiation of human induced pluripotent stem cells using gas-permeable membrane. Tissue Eng. Part 25, 457-467. doi: 10.1089/ten.tea.2018.0084

Kizawa, H., Nagao, E., Shimamura, M., Zhang, G., and Torii, H. (2017). Scaffold-free 3D bio-printed human liver tissue stably maintains metabolic functions useful for drug discovery. Biochem. Biophys. Rep. 10, 186-191. doi: 10.1016/j.bbrep.2017.04.004

Kvist, A. J., Kanebratt, K. P., Walentinsson, A., Palmgren, H., O’Hara, M., Björkbom, A., et al. (2018). Critical differences in drug metabolic properties of human hepatic cellular models, including primary human hepatocytes, stem cell derived hepatocytes, and hepatoma cell lines. Biochem. Pharmacol. 155, 124-140. doi: 10.1016/j.bcp.2018.06.026

Lauschke, V. M., Hendriks, D. F., Bell, C. C., Andersson, T. B., and Ingelman-Sundberg, M. (2016). Ingelman-Sundberg, M. Novel 3d culture systems for studies of human liver function and assessments of the hepatotoxicity of drugs and drug candidates. Chem. Res. Toxicol. 29, 1936-55. doi: 10.1021/acs.chemrestox.6b00150

Lemaigree, F. P. (2009). Mechanisms of liver development: concepts for understanding liver disorders and design of novel therapies. Gastroenterology 137, 62-79. doi: 10.1053/j.gastro.2009.03.035

Levy, G., Bomze, D., Heinz, S., Ramachandran, S. D., Noerenberg, A., Cohen, M., et al. (2015). Long-term culture and expansion of primary human hepatocytes. Nat. Biotechnol. 33, 1264-1271. doi: 10.1038/nbt.3377

Liu, L., Li, X., Huang, C., Bian, Y., Liu, X., Cao, J., et al. (2020). Bile acids, lipid and purine metabolism involved in hepatotoxicity of first-line anti-tuberculosis drugs. Expert Opin. Drug Metab. Toxicol. 16, 527-537. doi: 10.1080/17425255.2020.1758060

Luo, L., Schomaker, S., Houle, C., Aubrecht, J., and Colangelo, J. L. (2014). Evaluation of serum bile acid profiles as biomarkers of liver injury in rodents. Toxicol Sci. 137, 12-25. doi: 10.1093/toxsci/kft221

Luo., L., Aubrecht, J., Li, D., Warner, R. L., Johnson, K. J., et al. (2018). Assessment of serum bile acid profiles as biomarkers of liver injury and liver disease in humans. PLoS ONE 13:e0193824. doi: 10.1371/journal.pone.0193824

Maeda, K., and Sugiyama, Y. (2010). The use of hepatocytes to investigate drug uptake transporters. Methods Mol. Biol. 640, 327-353. doi: 10.1007/978-1-60761-688-7_18

Marion, T. L., Perry, C. H., St Claire, R. L. III., and Brouwer, K. L. (2012). Endogenous bile acid disposition in rat and human sandwich- cultured hepatocytes. Toxicol. Appl. Pharmacol. 261, 1-9. doi: 10.1016/j.taap.2012.02.002

Maschmeyer, I., Hasenberg, T., Jaenicke, A., Lindner, M., Lorenz, A. K., and Zech, J. (2015). Chip-based human liver-intestine and liver-skin co-cultures - a first step toward systemic repeated dose substance testing in vitro. Eur. J. Pharm. Biopharm. 95, 77-87. doi: 10.1016/j.ejpb.2015.03.002

Matsui, H., Osada, T., Moroshita, Y., Sekijima, M., Fujii, T., Takeuchi, S., et al. (2010). Rapid and enhanced repolarization in sandwich-cultured hepatocytes on an oxygen-permeable membrane. Biochem. Eng. J. 52, 255-262. doi: 10.1016/j.bej.2010.08.018

Matsui, H., Takeuchi, S., Osada, T., Fujii, T., and Sakai, Y. (2012). Enhanced bile canaliculi formation enabling direct recovery of biliary metabolites of hepatocytes in 3D collagen gel microcavities. Lab Chip 12, 1857-1864. doi: $10.1039 /$ c2lc40046d

Matsui, S., Harada, K., Miyata, N., Okochi, H., Miyajima, A., and Tanaka, M. (2018). Characterization of peribiliary gland-constituting cells based on differential expression of trophoblast cell surface protein 2 in biliary tract. Am. J. Pathol. 188, 2059-2073. doi: 10.1016/j.ajpath.2018.05.016

Miura, Y., Matsui, S., Miyata, N., Harada, K., Kikkawa, Y., and Ohmuraya, M. (2018). Differential expression of Lutheran/BCAM regulates biliary tissue remodeling in ductular reaction during liver regeneration. eLife 7:e36572. doi: $10.7554 /$ eLife.36572

Miyajima, A., Tanaka, M., and Itoh, T. (2014). Stem/progenitor cells in liver development, homeostasis, regeneration, and reprogramming. Cell Stem Cell 14, 561-574. doi: 10.1016/j.stem.2014.04.010

Nakao, Y., Kimura, H., Sakai, Y., and Fujii, T. (2011). Bile canaliculi formation by aligning rat primary hepatocytes in a microfluidic device. Biomicrofluidics 5:22212. doi: 10.1063/1.3580753

Navaneethan, U., Parsi, M. A., Gutierrez, N. G., Bhatt, A., Venkatesh, P. G., Lourdusamy, D., et al. (2014). Volatile organic compounds in bile can diagnose malignant biliary strictures in the setting of pancreatic cancer: a preliminary observation. Gastrointest. Endosc. 80, 1038-1045. doi: 10.1016/j.gie.2014. 04.016

Ni, X., Gao, Y., Wu, Z., Ma, L., Chen, C., Wang, L., et al. (2016). Functional human induced hepatocytes (hiHeps) with bile acid synthesis and transport capacities: a novel in vitro cholestatic model. Sci. Rep. 6:38694. doi: 10.1038/srep 38694

Nishimura, M., Yokoi, T., Tateno, C., Kataoka, M., Takahashi, E., Horie, T., et al. (2005). Induction of human CYP1A2 and CYP3A4 in primary culture of hepatocytes from chimeric mice with humanized liver. Drug Metab. Pharmacokinet. 20, 121-126. doi: 10.2133/dmpk.20.121

Ogimura, E., Tokizono, M., Sekine, S., Nakagawa, T., Bando, K., and Ito, K. (2017). Metabolic activation of cholestatic drug-induced bile acid-dependent toxicity in human sandwich-cultured hepatocytes. J. Pharm. Sci. 106, 2509-2514. doi: 10.1016/j.xphs.2017.04.050

Olinga, P., Merema, M., Hof, I. H., de Jong, K. P., Slooff, M. J., Meijer, D. K., et al. (1998). Effect of human liver source on the functionality of isolated hepatocytes and liver slices. Drug Metab. Dispos. 26, 5-11.

Oshikata-Miyazaki, A., and Takezawa, T. (2016). Development of an oxygenation culture method for activating the liver-specific functions of HepG2 cells utilizing a collagen vitrigel membrane chamber. Cytotechnology 68, 1801-1811. doi: 10.1007/s10616-015-9934-1

Penman, S. L., Sharma, P., Aerts, H., Park, B. K., Weaver, R. J., and Chadwick, A. E. (2019). Differential toxic effects of bile acid mixtures in isolated mitochondria and physiologically relevant HepaRG cells. Toxicol. Vitro 61:104595. doi: 10.1016/j.tiv.2019.104595

Perwaiz, S., Tuchweber, B., Mignault, D., Gilat, T., and Yousef, I. M. (2001). Determination of bile acids in biological fluids by liquid chromatographyelectrospray tandem mass spectrometry. J. Lipid Res. 42, 114-119. doi: 10.1016/S0022-2275(20)32342-7

Quinn, R. A., Melnik, A. V., Vrbanac, A., Fu, T., Patras, K. A., Christy, M. P., et al. (2020). Global chemical effects of the microbiome include new bile-acid conjugations. Nature 579, 123-129. doi: 10.1038/s41586-020-2047-9

Ramaiahgari, S. C., den Braver, M. W., Herpers, B., Terpstra, V., Commandeur, J. N., van de Water, B., et al. (2014). A 3D in vitro model of differentiated HepG2 cell spheroids with improved liver-like properties for repeated dose high-throughput toxicity studies. Arch. Toxicol. 88, 1083-1095. doi: 10.1007/s00204-014-1215-9

Rebelo, S. P., Costa, R., Estrada, M., Shevchenko, V., Brito, C., and Alves, P. M. (2015). HepaRG microencapsulated spheroids in DMSO-free culture: novel culturing approaches for enhanced xenobiotic and biosynthetic metabolism. Arch. Toxicol. 89, 1347-1358. doi: 10.1007/s00204-014-1320-9 
Ridlon, J. M., Kang, D. J., Hylemon, P. B., and Bajaj, J. S. (2014). Bile acids and the gut microbiome. Curr. Opin. Gastroenterol. 30, 332-338. doi: 10.1097/MOG.0000000000000057

Rizki-Safitri, A., Shinohara, M., Miura, Y., Danoy, M., Tanaka, M., Miyajima, A., et al. (2018). Efficient functional cyst formation of biliary epithelial cells using microwells for potential bile duct organisation in vitro. Sci. Rep. 8:11086. doi: 10.1038/s41598-018-29464-w

Rizki-Safitri, A., Shinohara, M., Tanaka, M., and Sakai, Y. (2020). Tubular bile duct structure mimicking bile duct morphogenesis for prospective in vitro liver metabolite recovery. J. Biol. Eng. 14:11. doi: 10.1186/s13036-020-0230-z

Rodrigues, A. D., Lai, Y., Cvijic, M. E., Elkin, L. L., Zvyaga, T., and Soars, M. G. (2014). Drug-Induced perturbations of the bile acid pool, cholestasis, and hepatotoxicity: mechanistic considerations beyond the direct inhibition of the bile salt export pump. Drug Metab. Dispos. 42, 566-574. doi: 10.1124/dmd.113.054205

Ruo,B, M., Vosough, M., Königsrainer, A., Nadalin, S., Wagner, S., Sajadian, S., et al. (2020). Towards improved hepatocyte cultures: Progress and limitations. Food Chem. Toxicol. 138, 1-44. doi: 10.1016/j.fct.2020.111188

Sakai, Y., Iwao, T., Susukida, T., Nukaga, T., Takemura, A., Sekine, S., et al. (2019). In vitro bile acid-dependent hepatocyte toxicity assay system using human induced pluripotent stem cell-derived hepatocytes: current status and disadvantages to overcome. Drug Metab. Pharmacokinet. 34, 264-271. doi: 10.1016/j.dmpk.2019.04.004

Samer, C. F., Lorenzini, K. I., Rollason, V., Daali, Y., and Desmeules, J. A. (2013). Applications of CYP450 testing in the clinical setting. Mol. Diagn. Ther. 17, 165-184. doi: 10.1007/s40291-013-0028-5

Sampaziotis, F., de Brito, M. C., Madrigal, P., Bertero, A., Saeb-Parsy, K., and Soares, F. (2015). Cholangiocytes derived from human induced pluripotent stem cells for disease modeling and drug validation. Nat. Biotechnol. 33, 845-852. doi: 10.1038/nbt.3275

Sarafian, M. H., Lewis, M. R., Pechlivanis, A., Ralphs, S., McPhail, M. J., Patel, V. C., et al. (2015). Bile acid profiling and quantification in biofluids using ultraperformance liquid chromatography tandem mass spectrometry. Anal. Chem. 87, 9662-9670. doi: 10.1021/acs.analchem.5b01556

Scherer, M., Gnewuch, C., Schmitz, G., and Liebisch, G. (2009). Rapid quantification of bile acids and their conjugates in serum by liquid chromatography-tandem mass spectrometry. J. Chromatogr. B 877, 3920-3925. doi: 10.1016/j.jchromb.2009.09.038

Setchell, K. D., Wolever, T. M., Vidgen, E., Kendall, C. W., Ransom, T. P., and Mehling, C. C. (1997). Bile acid concentrations in human and rat liver tissue and in hepatocyte nuclei. Gastroenterology 112, 226-235. doi: 10.1016/S0016-5085(97)70239-7

Shitara, Y., Li, A. P., Kato, Y., Lu, C., Ito, K., Itoh, T., et al. (2003). Function of uptake transporters for taurocholate and estradiol 17beta-D-glucuronide in cryopreserved human hepatocytes. Drug Metab. Pharmacokinet. 18, 33-41. doi: $10.2133 / \mathrm{dmpk} .18 .33$

Si-Tayeb, K., Noto, F. K., Nagaoka, M., Li, J., Battle, M. A., Duris, C., et al. (2010). Highly efficient generation of human hepatocyte-like cells from induced pluripotent stem cells. Hepatology 51, 297-305. doi: 10.1002/hep. 23354

Skardal, A., Aleman, J., Forsythe, S., Rajan, S., Murphy, S., Devarasetty, M., et al. (2020). Drug compound screening in single and integrated multi-organoid body-on-a-chip systems. Biofabrication 12:025017. doi: 10.1088/1758-5090/ab6d36

Soldatow, V. Y., Lecluyse, E. L., Griffith, L. G., and Rusyn, I. (2013). In vitro models for liver toxicity testing. Toxicol. Res. 2, 23-39. doi: 10.1039/C2TX20051A

Sun, P., Zhang, G., Su, X., Jin, C., Yu, B., Yu, X., et al. (2019). Maintenance of primary hepatocyte functions in vitro by inhibiting mechanical tension-induced yap activation. Cell Rep. 29, 3212-3222. doi: 10.1016/j.celrep.2019.10.128

Susukida, T., Sekine, S., Nozaki, M., Tokizono, M., Oizumi, K., Horie, T., et al. (2016). Establishment of a drug-induced, bile acid-dependent hepatotoxicity model using HepaRG cells. J. Pharm. Sci. 105, 1550-1560. doi: 10.1016/j.xphs.2016.01.013

Swift, B., Pfeifer, N. D., and Brouwer, K. L. (2010). Sandwich-cultured hepatocytes: an in vitro model to evaluate hepatobiliary transporter-based drug interactions and hepatotoxicity. Drug Metab. Rev. 42, 446-471. doi: $10.3109 / 03602530903491881$
Takahashi, Y., Hori, Y., Yamamoto, T., Urashima, T., Ohara, Y., and Tanaka, H. (2015). 3D spheroid cultures improve the metabolic gene expression profiles of HepaRG cells. Biosci. Rep. 35:00208. doi: 10.1042/BSR20150034

Tamai, M., Adachi, E., and Tagawa, Y. (2013). Characterization of a liver organoid tissue composed of hepatocytes and fibroblasts in dense collagen fibrils. Tissue Eng. Part A 19, 2527-2535. doi: 10.1089/ten.tea.2012.0704

Tanimizu, N., Kikkawa, Y., Mitaka, T., and Miyajima, A. (2012). $\alpha 1-$ and $\alpha 5-$ containing laminins regulate the development of bile ducts via $\beta 1$ integrin signals. J. Biol. Chem. 287, 28586-28597. doi: 10.1074/jbc.M112.350488

Tanimizu, N., Miyajima, A., and Mostov, K. E. (2007). Liver progenitor cells develop cholangiocyte-type epithelial polarity in three-dimensional culture. Mol. Biol. Cell 18, 1472-1479. doi: 10.1091/mbc.e06-09-0848

Tateno, C., Yoshizane, Y., Saito, N., Kataoka, M., Utoh, R., Yamasaki, C., et al. (2004). Near completely humanized liver in mice shows human-type metabolic responses to drugs. Am. J. Pathol. 165, 901-912. doi: 10.1016/S0002-9440(10)63352-4

Underhills, G. H., and Khetani, S. R. (2018). Bioengineered liver models for drug testing and cell differentiation studies. Cell Mol. Gastro Enterol. Hepatol. 5, 426-439. doi: 10.1016/j.jcmgh.2017.11.012

van Norman, G. A. (2019). Limitations of animal studies for predicting toxicity in clinical trials: is it time to rethink our current approach? J. Am. Coll. Cardiol. Basic Trans. Sci. 4, 845-854. doi: 10.1016/j.jacbts.2019.10.008

Vorrink, S. U., Ullah, S., Schmidt, S., Nandania, J., Velagapudi, V., Beck, O., et al. (2017). Endogenous and xenobiotic metabolic stability of primary human hepatocytes in long-term 3D spheroid cultures revealed by a combination of targeted and untargeted metabolomics. FASEB J. 31, 2696-2708. doi: 10.1096/fj.201601375R

Vyas, D., Baptista, P. M., Brovold, M., Moran, E., Gaston, B., Booth, C., et al. (2018). Self-assembled liver organoids recapitulate hepatobiliary organogenesis in vitro. Hepatology 67, 750-761. doi: 10.1002/hep.29483

Wang, Y., Wang, H., Deng, P., Chen, W., Guo, Y., Tao, T., et al. (2018). In situ differentiation and generation of functional liver organoids from human iPSCs in a 3D perfusable chip system. Lab Chip 18, 3606-3616. doi: 10.1039/C8LC00869H

Ware, B. R., Berger, D. R., and Khetani, S. R. (2015). Prediction of drug-induced liver injury in micropatterned co-cultures containing iPSC-derived human hepatocytes. Toxicol. Sci. 145, 252-262. doi: 10.1093/toxsci/kfv048

Watanabe, M., Zemack, H., Johansson, H., Hagbard, L., Jorns, C., Li, M., et al. (2016). Maintenance of hepatic functions in primary human hepatocytes cultured on xeno-free and chemical defined human recombinant laminins. PLoS ONE 11:e0161383. doi: 10.1371/journal.pone.0161383

Wolenski, F. S., Zhu, A., Johnson, M., Yu, S., Moriya, Y., Ebihara, T., et al. (2017). Fasiglifam (TAK-875) alters bile acid homeostasis in rats and dogs: a potential cause of drug induced liver injury. Toxicol. Sci. 157, 50-61. doi: 10.1093/toxsci/kfx018

Woolbright, B. L., Dorko, K., Antoine, D. J., Clarke, J. I., Gholami, P., Li, F., et al. (2015). Bile acid-induced necrosis in primary human hepatocytes and in patients with obstructive cholestasis. Toxicol. Appl. Pharmacol. 283, 168-177. doi: 10.1016/j.taap.2015.01.015

Woolbright, B. L., and Jaeschke, H. (2015). "Critical factors in the assessment of cholestatic liver injury in vitro," in Protocols in In Vitro Hepatocyte Research, Methods in Molecular Biology, eds M. Vinken, and V. Rogiers, Vol. 1250 (New York, NY: Springer Science+Business Media), 363-376. doi: 10.1007/978-1-4939-2074-7_28

Woolbright, B. L., McGill, M. R., Yan, H., and Jaeschke, H. (2016). Bile acid-induced toxicity in HepaRG cells recapitulates the response in primary human hepatocytes. Basic Clin. Pharmacol. Toxicol. 118, 160-167. doi: $10.1111 /$ bcpt.12449

Wu, F., Wu, D., Ren, Y., Huang, Y., Feng, B., Zhao, N., et al. (2019). Generation of hepatobiliary organoids from human induced pluripotent stem cells. J. Hepatol. 70, 1145-1158. doi: 10.1016/j.jhep.2018.12.028

Xiao, W., Perry, G., Komori, K., and Sakai, Y. (2015). New physiologically-relevant liver tissue model based on hierarchically cocultured primary rat hepatocytes with liver endothelial cells. Integr. Biol. 7, 1412-1422. doi: 10.1039/C5IB00170F

Xiao, W., Shinohara, M., Komori, K., Sakai, Y., Matsui, H., and Osada, T. (2014). The importance of physiological oxygen concentrations in the sandwich cultures of rat hepatocytes on gas-permeable membranes. Biotechnol. Prog. 30, 1401-1410. doi: 10.1002/btpr.1954 
Xu, X., Farach-Carson, M. C., and Jia, X. (2014). Three-dimensional in vitro tumor models for cancer research and drug evaluation. Biotechnol. Adv. 32, 1256-1268. doi: 10.1016/j.biotechadv.2014.07.009

Yamada, M., Hori, A., Sugaya, S., Yajima, Y., Utoh, R., Yamato, M., et al. (2015). Cell-sized condensed collagen microparticles for preparing microengineered composite spheroids of primary hepatocytes. Lab Chip 15, 3941-3951. doi: 10.1039/C5LC00785B

Yamasaki, C., Kataoka, M., Kato, Y., Kakuni, M., Usuda, S., Ohzone, Y., et al. (2010). In vitro evaluation of cytochrome P450 and glucuronidation activities in hepatocytes isolated from liver-humanized mice. Drug Metab. Pharmacokinet. 25, 539-550. doi: 10.2133/dmpk.DMPK-10-RG-047

Yamashiro, W., Maeda, K., Hirouchi, M., Adachi, Y., Hu, Z., and Sugiyama, Y. (2006). Involvement of transporters in the hepatic uptake and biliary excretion of valsartan, a selective antagonist of the angiotensin II AT1-receptor, in humans. Drug Metab. Dispos. 34, 1247-1254. doi: 10.1124/dmd.105.008938

Yan, S., Tang, J., Zhang, Y., Wang, Y., Zuo, S., Shen, Y., et al. (2017). Prostaglandin $\mathrm{E}_{2}$ promotes hepatic bile acid synthesis by an E prostanoid receptor 3-mediated hepatocyte nuclear receptor $4 \alpha /$ cholesterol $7 \alpha$-hydroxylase pathway in mice. Hepatology 65, 999-1014. doi: 10.1002/hep.28928

Yang, K., Guo, C., Woodhead, J. L., St Claire, R. L. 3rd, Watkins, P. B., Siler, S. Q., et al. (2016). Sandwich-cultured hepatocytes as a tool to study drug disposition and drug-induced liver injury. J. Pharm. Sci. 105: 443-459. doi: 10.1016/j.xphs.2015.11.008

Yang, T., Shu, T., Liu, G., Mei, H., Zhu, X., Huang, X., et al. (2017). Quantitative profiling of 19 bile acids in rat plasma, liver, bile and different intestinal section contents to investigate bile acid homeostasis and the application of temporal variation of endogenous bile acids. J. Steroid Biochem. 172, 69-78. doi: 10.1016/j.jsbmb.2017.05.015

Ying, F., Cai, Y., Wong, H. K., Chen, X. Y., Huang, I. B., Vanhoutte, P. M., et al. (2018). EP4 emerges as a novel regulator of bile acid synthesis and its activation protects against hypercholesterolemia. BBA Mol. Cell Biol. L 1863, 1029-1040. doi: 10.1016/j.bbalip.2018.06.003

Zeigerer, A., Wuttke, A., Marsico, G., Seifert, S., Kalaidzidis, Y., and Zerial, M. (2017). Functional properties of hepatocytes in vitro are correlated with cell polarity maintenance. Exp. Cell Res. 350, 242-252. doi: 10.1016/j.yexcr.2016.11.027

Zhou, Q., Patel, D., Kwa, T., Haque, A., Matharu, Z., Stybayeva, G., et al. (2015). Liver injury-on-a-chip: microfluidic co-cultures with integrated biosensors for monitoring liver cell signaling during injury. Lab Chip 15, 4467-4478. doi: 10.1039/C5LC00874C

Conflict of Interest: The authors declare that the research was conducted in the absence of any commercial or financial relationships that could be construed as a potential conflict of interest.

Copyright (C) 2021 Rizki-Safitri, Tokito, Nishikawa, Tanaka, Maeda, Kusuhara and Sakai. This is an open-access article distributed under the terms of the Creative Commons Attribution License (CC BY). The use, distribution or reproduction in other forums is permitted, provided the original author(s) and the copyright owner(s) are credited and that the original publication in this journal is cited, in accordance with accepted academic practice. No use, distribution or reproduction is permitted which does not comply with these terms. 